\title{
IMPACT OF TRANSMUTATIONS IN FUSION ENVIRONMENT ON FLIBE CHEMISTRY
}

\author{
by \\ Dai-Kai Sze \\ Argonne National Laboratory, Argonne, IL 60439, USA \\ Mohamed E. Sawan \\ University of Wisconsin, Madison, WI 53706, USA \\ Edward. T. Cheng \\ TSI Research, Inc. Solana Beach, CA 92075, USA
}

\begin{abstract}
Transmutation rates of $\mathrm{Li}, \mathrm{Be}$ and $\mathrm{F}$ are calculated for a typical flibe blanket. The results concluded that the transmutation rate of $F$ is more than double that of Be. Because of the high destruction rate of fluorine, there will be no free fluorine in the molten salt.

Therefore, experimental program to address the chemistry control of flibe does not have to worry about the issues associated with free fluorine. Also, this calculation defines the chemical of flibe after irradiation. This chemical state needs to be simulated closely for the flibe chemistry control experiment.
\end{abstract}

\section{Introduction:}

Flibe is a molten salt of $\mathrm{LiF}$ and $\mathrm{BeF}_{2}$, which is a candidate for the breeding material and coolant for D-T fusion reactors $(1,2)$. One of the key problems for flibe fusion reactor blankets is caused by the transmutation of lithium and beryllium (3). The fluorine associated with the $\mathrm{LiF}$ and $\mathrm{BeF}_{2}$ will be freed by these transmutations to form either free fluorine or hydrogen fluoride. Both free fluorine and tritium fluoride are corrosive to structural materials. The free fluorine is a particular concern. While tritium fluoride will be compatible with some structural materials, free fluorine is not compatible with any structural materials. Controlling the activities of free fluorine and TF must be resolved if flibe is going to be used as the coolant and breeding material in fusion systems.

Earlier work concerned the transmutation rates of lithium and beryllium (4). The transmutation of lithium forms tritium, and tritium will combine with fluorine from $\mathrm{LiF}$ to form tritium fluoride. On the other hand, the transmutation of Be forms He. Therefore, the F released from the $\mathrm{Be}$ transmutation becomes free fluorine. Since free fluorine will react with any structural material, its activity has to be controlled to an acceptable level. One of the possible methods is to add $\mathrm{Be}$ into the flibe stream to combine the free fluorine back to $\mathrm{BeF}_{2}$. While this 


\section{DISCLAIMER}

This report was prepared as an account of work sponsored by an agency of the United States Government. Neither the United States Government nor any agency thereof, nor any of their employees, make any warranty, express or implied, or assumes any legal liability or responsibility for the accuracy, completeness, or usefulness of any information, apparatus, product, or process disclosed, or represents that its use would not infringe privately owned rights. Reference herein to any specific commercial product, process, or service by trade name, trademark, manufacturer, or otherwise does not necessarily constitute or imply its endorsement, recommendation, or favoring by the United States Government or any agency thereof. The views and opinions of authors expressed herein do not necessarily state or reflect those of the United States Government or any agency thereof. 


\section{DISCLAIMER}

Portions of this document may be illegible in electronic image products. Images are produced from the best available original document. 
chemical reaction will proceed forward from thermodynamics consideration, there is no assurance if the reaction rate is fast enough kinetically.

Recent work from a safety experiment called FLIQURE (5) concluded that the transmutation rate of fluorine is rather high. If the transmutation rate of $F$ is high enough, this transmutation may offset the release of fluorine by the transmutation of Be. Since the molecular form is $\mathrm{BeF}_{2}$, the transmutation rate of fluorine has to be at least two times as high as the transmutation rate of the beryllium to eliminate al the free fluorine. If the transmutation rate of fluorine is high enough to remove all the free fluorine, the only chemical compound we have to worry about from the transmutation process will be tritium fluoride.

Neutronic calculations for a typical flibe blanket in fusion environment were performed to determine the transmutation rate of the $\mathrm{Li}, \mathrm{Be}$ and $\mathrm{F}$ in flibe. The transmutation rates were used to determine the amount of free $\mathrm{T}, \mathrm{Li}, \mathrm{F}$ and $\mathrm{Be}$ produced. The results indicate that we will have sufficient $\mathrm{Be}$, freed from the transmutation of $\mathrm{F}$, to react with the free $\mathrm{F}$, formed from the transmutation of Be. From these results, it can be concluded that, at least from mass balance considerations, there will be no free fluorine in the salt after irradiation. This removes the concern of corrosion by free fluorine. The only concern will be the corrosion by the TF. Since TF is far less corrosive than free fluorine, this opens up more possibilities for the chemical control process in flibe system.

RECEIVED

\section{Flibe Chemistry:}

DEC 0 \& 2000

Flibe is a molten salt of $\mathrm{LiF}$ and $\mathrm{BeF}_{2}$, which is the coolant for the Molten Salt Reactor Experiment (MSRX) (6). While pure flibe is compatible with many different structural materials, flibe can be very corrosive if there are impurities. For the fusion and fission applications, the impurities are introduced into the salt by the following transmutation reactions:

Those transmutations of $\mathrm{Li}$ and $\mathrm{Be}$ release the fluorine in the salt to form either free fluorine or TF. For the breeder application, there is a build in REDOX (Reduction-Oxidation) to control the $\mathrm{F}$ and $\mathrm{TF}$ activities:

$$
\begin{gathered}
\mathrm{UF}_{3}+\mathrm{F}-\rightarrow-\mathrm{UF}_{4}: \\
\mathrm{UF}_{3}+\mathrm{TF}-\mathrm{UF}_{4}+0.5 \mathrm{~T}_{2}
\end{gathered}
$$

For fusion system, a REDOX reaction has to be developed.

The corrosion process starts with the structural materials to be oxidized to form fluoride. The metallic fluoride will be dissolved in the salt to be carried away. The free energy of formation determines if an oxidation reaction will go forward. Therefore, the free energy of formation of different fluorides provides a good indication if the material is compatible with flibe. Table 1 summarizes the free energy of formations of some metallic fluorides (6), 
Table 1. Free Energies of Formation of Fluorides

\begin{tabular}{|c|c|}
\hline Material & $\begin{array}{c}\text { Free Energy of Formation } \\
\left(\mathrm{Kcal} / \mathrm{g} \text {-atom at } 1000^{\circ} \mathrm{C}\right)\end{array}$ \\
\hline $\mathrm{MoF}_{6}$ & -50.2 \\
\hline $\mathrm{WF}_{6}$ & -56.8 \\
\hline $\mathrm{NiF}_{2}$ & -55.3 \\
\hline $\mathrm{VF}_{3}$ & -58.0 \\
\hline $\mathrm{VF}_{4}$ & -66.0 \\
\hline $\mathrm{HF}$ & -66.2 \\
\hline $\mathrm{FeF}_{2}$ & -66.5 \\
\hline $\mathrm{NbF}_{5}$ & -72.5 \\
\hline $\mathrm{CrF}_{2}$ & -75.2 \\
\hline $\mathrm{TaF}_{5}$ & -82.2 \\
\hline $\mathrm{TiF}_{4}$ & -85.4 \\
\hline $\mathrm{BeF}_{2}$ & -106.9 \\
\hline $\mathrm{LiF}$ & -125.2 \\
\hline & \\
\hline
\end{tabular}

As we go down this table, the salt becomes more stable, while the metallic element becomes less stable. Both $\mathrm{BeF}_{2}$ and $\mathrm{LiF}$ are very stable, and will not react with any structural materials to form metallic fluoride. $\mathrm{HF}$ is stable with $\mathrm{Mo}, \mathrm{W}, \mathrm{Ni}$ and maybe $\mathrm{V}$. This is the reason that the MSRX selected high Ni alloy as the structural material. However, free fluorine reacts with all the materials on this table. This is the reason that the controlling of free fluorine in a flibe system is so important.

\section{Neutronic Results:}

The FLIQURE experiment (.5) uses Ca-252 as neutron source to study activation issues and its impact on safety. The results from FLIQURE calculations concluded that the transmutation rate of $\mathrm{F}$ is about $7 \times 10^{9}$ atoms per hour, while the transmutation rate of $\mathrm{Be}$ is $1.1 \times 10^{6}$ atoms per hour. The transmutation rate of $\mathrm{F}$, under $\mathrm{Ca}-252$ spectrum, is rather high, but not high enough to destroy all the free $\mathrm{F}$ resulted from the transmutation of Be. Since the neutron spectrum is fusion reactor blanket is very different from the FLIQURE, the transmutation rates of $\mathrm{Be}$ and $\mathrm{F}$ in fusion spectrum were calculated.

The neutronic model used to do this calculation assumes a $70 \mathrm{~cm}$ blanket with flibe only. The chemical form of the flibe used is $\mathrm{Li}_{2} \mathrm{BeF}_{4}$. All the results are normalized to one DT neutron source. The results of the calculation are summarized on Table 2. These destruction rates include all transmutation reactions such as (n,alpha), $(n, \alpha),\left(n, n^{\prime} \alpha\right),(n, p),(n, d),(n, t),\left(n, n^{\prime} p\right)$. The transmutation rates of all the constituents in flibe are listed on Table 3. 
Table 2. Results of Neutronic Calculation

\begin{tabular}{|c|c|}
\hline Tritium production rate in lithium & 1.27 \\
\hline He production rates & \\
\hline From lithium & 1.30 \\
\hline From Be & 0.41 \\
\hline From fluorine & 0.50 \\
\hline Total & 2.21 \\
\hline H production rates & \\
\hline From lithium & 1.30 \\
\hline From Be & 0.003 \\
\hline From fluorine & 0.102 \\
\hline Total & 1.41 \\
\hline
\end{tabular}

Table 3. Transmutation Rates for Flibe Constituents

\begin{tabular}{|l|c|}
\hline Lithium destruction rate & 1.33 \\
\hline Be destruction rate & 0.208 \\
\hline Fluorine destruction rate & 0.602 \\
\hline Ratio of destruction rate of $\mathrm{F}$ to $\mathrm{Be}$ & 2.9 \\
\hline
\end{tabular}

Table 4.

The atomic balance of the transmutation products per DT fusion are summarized on

Table 4. Atomic Balance of the Transmutation Products

\begin{tabular}{|l|c|}
\hline Free tritium & 1.27 \\
\hline Free lithium (from $\mathrm{F}$ transmutation) & 0.30 \\
\hline Free Fluorine & \\
\hline \multicolumn{1}{|c|}{ From lithium transmutation } & 1.33 \\
\hline \multicolumn{1}{|c|}{ From Be transmutation } & 0.22 \\
\hline \multicolumn{1}{|c|}{ Total } & 1.746 \\
\hline Free Be (from F transmutation) & 0.15 \\
\hline Fluorine combined with T to form TF & 1.27 \\
\hline Fluorine combined with $\mathrm{F}$ to form $\mathrm{LiF}$ & 0.30 \\
\hline Free fluorine left & 0.175 \\
\hline Be required to form $\mathrm{BeF}_{2}$ & 0.088 \\
\hline Extra Be after the formation of $\mathrm{BeF}_{2}$ & 0.062 \\
\hline
\end{tabular}


From this results, it can be concluded that there will be more than enough $\mathrm{Be}$ in the transmutation product to react with all free fluorine to form $\mathrm{BeF}_{2}$. Similar conclusion was obtained for flibe blanket that use separate Be multiplier to improve tritium breeding.

This is a very encouraging result. Free fluorine is one of the most difficult materials to handle, and it will react with any structural material for the blanket and for the heat transport system. This result concluded that, at least from mass balance and from thermodynamics point of view, there would be no free fluorine in flibe. Also, there will be some extra $\mathrm{Be}$ in the system to form as reducing agent to control other possible impurities in flibe. Therefore, we can safely assume that the blanket is in a reducing environment, which is advantageous from material compatibility point of view. However, since there is extra $B e$ to reduce the TF to the $T_{2}$ form, the tritium partial pressure will be high, and tritium control will be an issue.

\section{Conclusions:}

The transmutation of $\mathrm{Li}$ and $\mathrm{Be}$ to form $\mathrm{TF}$ and free fluorine have been a concern to cause material compatibility issues between flibe under irradiation and structural materials. Of particular concern is the formation of free fluorine because it is very corrosive to all structural materials. Neutronic calculations concluded that the destruction rate of fluorine is so high that free fluorine will not exist in a fusion reactor blanket. This result may reduce the concern about the problems associated with flibe chemistry control process. If the kinetics of the combination of $\mathrm{Be}$ and $\mathrm{F}$ to form $\mathrm{BeF}_{2}$ is fast enough, we will only have to worry about how to control the TF activity, which is much less of a concern than the $F_{2}$ activity.

Also, those results can be used to form the reference case for the experimental program to assess the flibe chemistry control process. The species in the flibe system after irradiation has been defined. Therefore, it will be necessary to form the chemical state of the flibe to be similar to that of Table 4.

\section{References:}

1. A. Sagara, et. al., "Design Studies of Helical-type Fusion Reactor FFHR," Proceedings of the Fourth International Symposium on Fusion Nuclear Technology, Tokyo, Japan, April 6-11, 1997.

2. R. Moir, et. al., "HYLIFE-II Progress Report" UCID-21816, LLNL Report, December, 1991

3. Dai-Kai Sze, et. al., "Flibe assessment", to be presented at the ANS 14th TOFE.

4. W. R. Grimes and Stanley Canter, " Molten Salt as Blanket fluid in Controlled Fusion Reactors," in the Chemistry of Fusion Technology, Edited by Dieter M. Gruen, Plenum Press, 1972. 
5. J. W. Sterbentz et. al., " Design of the FLIQURE Experiment" to be presented at the ANS 14th TOFE.

6. W. R. Grimes, "Molten Salt Reactor Chemistry," Nucl. Appl. Tech., 8, 137 (1970).

7. Kathy McCarthy, INEEL, Private Communication, 2000.

8. J. C. R. Hunt and R. Hancox," The Use of Liquid Lithium as Coolant in a Toroidal Fusion Reactor, Part 1, Calculation of pumping power," CLM-R 115, U.K. Atomic Energy Authority, Culham Laboratory, Abington, England (1971).

9. S. Kakac, R. K. Shah, W. Aung, "Handbook of Single-phase Convection Heat Transfer," John Wiley \& Sons, 1987 , 